\title{
REDES FAMILIARES NA EMIGRAÇÃO VALADARENSE PARA OS ESTADOS UNIDOS
}

\author{
Wilson Fusco*
}

$\triangle 1$ migração de brasileiros para o exterior, como um processo contínuo e de volume expressivo, é um evento extremamente recente. Os estudos já publicados concordam que o movimento aparece de forma consistente a partir da segunda metade da década de 1980, e a situação de Governador Valadares' não é diferente (Sales, 1995 e 1999; Assis, 1995; Soares, 1995; Martes, 1999). Essa característica é acompanhada de configuração e dinâmica próprias de um fluxo em formação, no qual predominam jovens trabalhadores do sexo masculino, que iniciam o movimento com a forte expectativa de voltar a viver no Brasil. Os pioneiros criam novos laços no destino, sem perder as conexões com a origem, facilitando assim o engajamento de novos migrantes no movimento, o que alimenta um processo cumulativo.

A ampliaçãodo contingente populacional disponível para a migração vai aos poucos transformando o quadro inicial, no qual começam a se inserir, cada vez mais, mulheres e indivíduos de diversas faixas de idade, e a reunificação familiar também começa a ser um motivo comum para migrar. As redes migratórias, que ampliam suas conexões no decorrer do processo, passam a desempenhar especial papel na redefinição da expectativa temporal do migrante. Indivíduos que se dispuseram a viver um período limitado de sacrifício e solidão sentem-se mais a vontade, no interior de um grupo de conhecidos, para continuar sua experiência por mais tempo que o planejado, às vezes para o resto da vida.
De acordo com Tilly (1990), os novos fluxos migratórios que têm os Estados Unidos como destino não podem ser explicados somente pelo diferencial de salários (push and pull theory) entre este e os países de origem dos migrantes, especialmente porque os processos migratórios são altamente seletivos por origem e tipo de migrante. Essa argumentação chama a atenção para questões às quais os neoclássicos ainda não deram resposta. Por que nos países pobres certos indivíduos migram e outros não? Por que alguns locais específicos no destino atraem mais migrantes que outros, com estrutura de mercado de trabaIho semelhante? A resposta, segundo Tilly e Massey, está na criação e atuação das redes sociais, responsáveis pela construção dos vínculos necessários para a emigração, pela veiculação do conjunto de informações e percepções que os indivíduos necessitam para emigrar. O conceito de redes sociais na migração internacional, portanto, pode ser utilizado para completar algumas lacunas deixadas nesse campo teórico.

Este trabalho ${ }^{2}$ pretende contribuir para aprofundar as questões acima, referentes ao fluxo Governador Valadares-Estados Unidos, e ainda analisar outras questões particulares, como o apoio fornecido pelas relações de parentesco e amizade e as estratégias de migração. Para tanto, vamos focalizar a presen- ça e o uso das redes sociais próprias desse movimento, considerando de forma especial a dinâmica temporal do processo.

\section{CONCENTRAÇÃO NO DESTINO}

A rota que leva aos Estados Unidos é a marca registrada do fluxo que parte de Governador Valadares. Segundo a Tabela 1 , mais de $85 \%$ dos valadarenses escolheram os EUA como destino em sua primeira viagem ao exterior. A proporção de migrantes com experiência nos EUA sobe para $88,7 \%$, quando consideramos também os indivíduos que, tendo inicialmente escolhido outro país em sua primeira viagem,

\begin{tabular}{|c|c|c|}
\hline \multicolumn{3}{|c|}{$\begin{array}{c}\text { TABELA 1 } \\
\text { País de Destino na Primeira Viagem } \\
\text { do Migrante aos EUA. } \\
\text { Governador Valadares, } 1997\end{array}$} \\
\hline \multirow[t]{2}{*}{ País de Destino } & \multicolumn{2}{|c|}{ População Migrante } \\
\hline & № & $\%$ \\
\hline Estados Unidos & 440 & 85,6 \\
\hline Canadá & 13 & 2,5 \\
\hline Portugal & 12 & 2,3 \\
\hline Austrália & 7 & 1,4 \\
\hline Outros & 42 & 8,2 \\
\hline Total & 514 & 100,0 \\
\hline \multicolumn{3}{|c|}{$\begin{array}{l}\text { Fonte: Pesquisa amostral } \\
\text { Total de casos: } 537 \\
\text { Casos válidos: } 514\end{array}$} \\
\hline
\end{tabular}


decidem-se pelos Estados Unidos num momento posterior.

A situação de crise econômica pela qual passou a população de Governador Valadares, associada ao imaginário criado pela presença de norte-americanos na cidade, são os fatores mais freqüentemente utilizados para explicar o início do fluxo para os EUA (Sales, 1999; Assis, 1999; So-

\begin{tabular}{|c|c|c|}
\hline \multicolumn{3}{|c|}{$\begin{array}{c}\text { TABELA } 2 \\
\text { Estados e Principais Cidades de } \\
\text { Destino na Primeira Viagem } \\
\text { do Migrante aos EUA. } \\
\text { Governador Valadares, } 1997\end{array}$} \\
\hline $\begin{array}{l}\text { Estado e principais } \\
\text { cidades de destino }\end{array}$ & \multicolumn{2}{|c|}{$\begin{array}{l}\text { População } \\
\text { Migrante }\end{array}$} \\
\hline Massachusetts & 208 & 51,2 \\
\hline Boston & 144 & 35,5 \\
\hline Framingham & 19 & 4,7 \\
\hline Somerville & 9 & 2,2 \\
\hline Marlborough & 11 & 2,7 \\
\hline Bridgeport & 9 & 2,2 \\
\hline Hudson & 5 & 1,2 \\
\hline Outras & 11 & 2,7 \\
\hline Flórida & 61 & 15,0 \\
\hline Pompano Beach & 15 & 3,7 \\
\hline Deerfield Beach & 14 & 3,4 \\
\hline Miami & 14 & 3,4 \\
\hline Palm Beach & 3 & 0,7 \\
\hline Boca Raton & 3 & 0,7 \\
\hline Outras & 12 & 3,0 \\
\hline New Jersey & 59 & 14,5 \\
\hline Newark & 21 & 5,2 \\
\hline Lincoln & 5 & 1,2 \\
\hline Elizabeth & 4 & 1,0 \\
\hline Outras & 29 & 7,1 \\
\hline New York & 46 & 11,3 \\
\hline New York & 36 & 8,9 \\
\hline Fallsburg & 3 & 0,7 \\
\hline Outras & 7 & 1,7 \\
\hline Outros Estados & 32 & 8,0 \\
\hline Total & 406 & 100,0 \\
\hline \multicolumn{3}{|c|}{$\begin{array}{r}\text { Fonte: } \text { Pesquisa amostral } \\
\text { Total de casos: } 456 \\
\text { Casos válidos: } 406\end{array}$} \\
\hline
\end{tabular}

ares, 1995; Scudeler, 1999). Já a distribuição espacial do contingente de migrantes nos limites do território norte-americano é uma questão ainda pouco explorada, que merece algumas considerações.

$\mathrm{O}$ reconhecimento dos pontos de destino mais expressivos de um determinado fluxo permite uma caracterização adicional de sua dinâmica. Para citar um exemplo, vejamos a comunidade brasileira em São Francisco, nos Estados Unidos. Segundo Ribeiro (1999), dados do consulado brasileiro mostram que podemos encontrar migrantes de vários estados do Brasil, mas que a concentração de goianos é a expressão mais evidente. $\mathrm{E}$ os indivíduos que saem de Governador Valadares, onde se concentram? A Tabela 2 mostra o destino desses brasileiros em sua primeira viagem aos EUA.

Observando os locais de destino com maior concentração de brasileiros, destaca-se, em primeiro lugar, a cidade de Boston, que sozinha é responsável por um terço dessas migrações. Vem em seguida a cidade de New York, com 8,9\%; Newark, com $5,2 \%$; e Framingham, que faz parte da região metropolitana de Boston, com $4,7 \%$. No Estado da Flórida se destacam as cidades de Pompano Beach, Deerfield Beach e Miami, porém todas com contingentes de valadarenses que representam apenas $3 \%$ sobre o total.

O município de Framingham abriga uma das mais notáveis comunidades de imigrantes brasileiros, prove- nientes principalmente de Governador Valadares. Segundo Bicalho (1989), 87\% dos residentes em Framingham vieram do Vale do Rio Doce. Teresa Sales (1999), que dedicou um capítulo especial à cidade norte-americana, relata o sentimento de identidade provocado pela predominância de brasileiros no local.

"Ao sair novamente à rua, apesar do frio de outono daquele final de tarde apressado em escurecer mais cedo, me sinto brasileirinha da silva. Tão brasileira depois daquela coxinha de galinha e daquele suco de caju, que estranhei quando, na rua, me deparei com dois autênticos nativos conversando em inglês. "3 p. 47

Os valadarenses, portanto, formam comunidades importantes em quatro Estados dos EUA, mas a concentração de mais de $51 \%$ em Massachusetts evidencia este como o principal ponto de destino desses brasileiros. Essa informação também pode ser encontrada nos trabalhos de Sales (1999), Martes (1998) e Bicalho (1989), que pesquisaram sobre a origem dos imigrantes brasileiros nos Estados Unidos.

Uma vez que a chegada dos brasileiros em território dos Estados Unidos acontece continuamente, podemos concluir que muitos migrantes seguiram paulatinamente para locais onde já se encontravam seus conterrâneos. Este é um dos aspectos das redes sociais, que, segundo Sales “....contribuem não apenas para fornecer os referenciais do local de destino, como a acomodação inicial do imigrante e sua inserção no mercado de trabalho" (Sales, 1999, p. 36).

A Tabela 3 mostra o Estado de destino

\begin{tabular}{|c|c|c|c|}
\hline \multicolumn{4}{|c|}{$\begin{array}{c}\text { TABELA } 3 \\
\text { Estado de Destino segundo o Período de Migração } \\
\text { Primeira Viagem aos EUA / Governador Valadares, } 1997\end{array}$} \\
\hline \multirow[t]{2}{*}{ Estado de destino } & \multicolumn{3}{|c|}{ Período da Migração } \\
\hline & 67 a 86 & 87 a 89 & 90 a 97 \\
\hline Massachusetts (\%) & 45,1 & 50,6 & 58,5 \\
\hline Florida (\%) & 18,9 & 13,9 & 12,7 \\
\hline New Jersey (\%) & 12,3 & 16,3 & 14,4 \\
\hline New York (\%) & 18,0 & 10,8 & 5,1 \\
\hline Outros (\%) & 5,7 & 8,4 & 9,3 \\
\hline Total (\%) & 100,0 & 100,0 & 100,0 \\
\hline Total ( $\left.\mathrm{N}^{2}\right)$ & 122 & 166 & 118 \\
\hline
\end{tabular}


do migrante em função do período da primeira viagem aos EUA. Massachusetts atrai $45,1 \%$ dos migrantes que fizeram sua primeira viagem até 1986; essa concentração aumenta para $50,6 \%$ no segundo período, e cresce ainda mais no período mais recente, chegando a contar com $58,5 \%$ dos migrantes que saíram do Brasil entre os anos de 1990 e 1997. O fluxo que se direciona para o Estado de New Jersey tem um crescimento tímido entre o primeiro e último períodos de primeiras viagens, passando de $12,3 \%$ para $14,4 \%$. O que se verifica para os Estados da Florida e de New York é uma diminuição contínua da concentração de migrantes: com 18,9\% e $18,0 \%$, respectivamente, no primeiro período, a proporção de indivíduos que escolhem esses Estados como destino em sua primeira viagem cai para $12,7 \%$ e $5,1 \%$ no último período.

O direcionamento de fluxos migratórios para pontos específicos de destino foi também estudado por Massey (1987). Esse autor descreve a formação de comunidades de migrantes, que ele chamou de "comunidades filhas", como um processo intrínseco da migração. Os primeiros momentos da migração de mexicanos para os EUA comportam uma diversidade muito maior de destinos do que nos períodos mais recentes. É um processo social que leva tempo para operar, de modo que as comunidades filhas se desenvolvem mais devagar no começo, e depois mais rapidamente, quando um volume maior de migrantes sustenta as redes de forma mais sólida, fato que exerce um efeito magnético para as migrações subsequentes.

O desenvolvimento de comunidades estabelecidas nos Estados Unidos é um passo crucial na maturação das redes migratórias. Quando alguns indivíduos se fixam em determinados lugares o processo migratório se transforma, redirecionando os fluxos para regiões específicas (Massey, 1987). Visto desse modo, em todo local que se forma uma comunidade de imigrantes, a atração para novos migrantes é um fato consumado. Mas não é isso o que observamos no caso analisado. Enquanto que, proporcionalmente ao total de pessoas em cada período, o Estado de Massachusetts recebe cada vez mais indivíduos, decresce o número relativo de migrantes que se di- rigem aos outros Estados, com exceção de New Jersey, que mantém certa estabilidade.

O que ocorre é que não basta a aglomeração de pessoas no destino para que existam os benefícios que facilitam e estimulam o ingresso de pessoas num fluxo migratório. A formação de comunidades no destino é uma condição necessária, mas não suficiente. É preciso que se desenvolvam redes de relações confiáveis unindo origem e destino, nas quais o migrante em potencial possa se apoiar. As diferenças verificadas na Tabela 3 podem ser explicadas em função desse argumento, ou seja, as regiões que mais atraem migrantes são as que melhor disponibilizam os recursos característicos das redes migratórias (Fusco, 2000).

\section{USO DAS REDES}

Um dos aspectos mais marcantes para o indivíduo que decide pela migração é a sua primeira viagem ao exterior. Desde os preparativos para o embarque, até a chegada no destino, o migrante enfrenta vários desafios. Por isso, é importante sabermos como ele passa pela primeira etapa de seu empreendimento. A Tabela 4 mostra com quem o migrante viajou pela primeira vez aos EUA.

\begin{tabular}{|l|cc|}
\hline \multicolumn{3}{|c|}{$\begin{array}{c}\text { TABELA 4 } \\
\text { Tipo de Migração } \\
\text { Primeira Migração Internacional } \\
\text { com Destino aos EUA } \\
\text { Governador Valadares, 1997 }\end{array}$} \\
\hline Tipo de Migração & № & $\%$ \\
\hline Sozinho & 347 & 76,8 \\
Com a família & 68 & 15,0 \\
Grupo de migrantes & 26 & 5,8 \\
Outra & 11 & 2,4 \\
\hline Total & 452 & 100,0 \\
\hline \multicolumn{3}{|c|}{ Fonte: Pesquisa amostral } \\
Total de casos: 456 \\
Casos válidos: 452 \\
\hline \multicolumn{3}{|c|}{}
\end{tabular}

De acordo com a Tabela $4,76,8 \%$ da população migrante enfrenta a primeira viagem aos Estados Unidos, desacompanhado. Uma parcela correspondente a $15,0 \%$ viajou com a família e $5,8 \%$ foi em grupo, com outros migrantes. Pelo menos duas conclusões diferentes podem ser alcançadas a partir desses dados, dependendo da perspectiva em que se coloca a melhor estratégia ao migrar. Nesse caso, as possibilidades estratégicas estariam entre enfrentar a primeira viagem só ou em grupo.

Se o problema maior enfrentado pelo indivíduo, no período inicial da sua experiência migratória, ocorresse durante o trajeto da primeira viagem, então ele teria mais segurança se pudesse contar com a companhia de parentes ou outros migrantes. Nesse caso, poderíamos supor que a estrutura de relações sociais que liga Governador Valadares aos Estados Unidos é frágil, e não oferece condições satisfatórias ao desenvolvimento do processo migratório.

Por outro lado, poderíamos partir do princípio de que o migrante valadarense considera que a viagem solitária é a estratégia de menor risco. Na verdade, as características desse movimento, tais como a distância entre origem e destino e a predominância de ilegais no fluxo, indicam que o indivíduo tem mais chances, ao enfrentar a primeira experiência migratória, viajando sozinho. E para que o migrante possa concretizar seus planos, ele precisa contar com uma rede de relações sociais bem desenvolvida, na origem e no destino. Dessa forma, podemos deduzir que a estrutura de laços sociais é bastante forte na comunidade de migrantes valadarenses, e dá condições para que a estratégia de viagem mais apropriada seja adotada. Dentre as duas hipóteses apresentadas, acreditamos que esta última corresponda melhor à realidade, e basearemos nossa argumentação nos demais resultados do survey.

Cabe ressaltar que a estratégia de migração individual não se confunde com a decisão individual de migrar. O primeiro caso diz respeito à opção de migrar sem acompanhantes, de acordo com os motivos descritos acima. Já a segunda situação diz respeito à idéia de que o indivíduo decide sozinho pela migração, sem o consen- 


\begin{tabular}{|c|c|c|}
\hline \multicolumn{3}{|c|}{$\begin{array}{c}\text { TABELA } 5 \\
\text { Fonte de Recursos Financeiros } \\
\text { para o Migrante } \\
\text { Primeira Migração Internacional } \\
\text { com Destino aos EUA } \\
\text { Governador Valadares, } 1997\end{array}$} \\
\hline $\begin{array}{l}\text { Origem dos } \\
\text { Recursos }\end{array}$ & № & $\%$ \\
\hline Próprios & 201 & 45,2 \\
\hline Parentes & 178 & 40,0 \\
\hline Amigos & 38 & 8,6 \\
\hline Igreja & 1 & 0,2 \\
\hline Agência & 18 & 4,1 \\
\hline Empresa & 2 & 0,4 \\
\hline Banco & 5 & 1,1 \\
\hline Namorado & 2 & 0,4 \\
\hline Total & 445 & 100,0 \\
\hline \multicolumn{3}{|c|}{ Fonte: Pesquisa amostral } \\
\hline
\end{tabular}

so de seus familiares. Como dissemos antes, acreditamos que a decisão de migrar é, na maior parte das vezes, coletiva, e ocorre de acordo com a estratégia familiar.

\section{Assistência financeira}

Até que o imigrante consiga seu primeiro salário, geralmente ele passa por um período de carência. Antes mesmo de embarcar, os gastos com passagens e documentação começam a selecionar quem vai e quem fica. Depois, no destino, a assistência financeira para os primeiros dias de acomodação aumenta as chances dos "novatos". Após analisar os dados sobre assistência financeira ao migrante mexicano, Massey afirma que "(...)família e amigos são um inestimável recurso sócio-econômico para migrantes nos EUA" (Massey, 1987, p.152).

No survey realizado em Governador Valadares foi incluída uma questão sobre a principal fonte de recursos que o migrante utilizou em sua primeira viagem aos Estados Unidos. Os resultados estão na Tabela 5.

A Tabela 5 mostra a importância que têm as redes migratórias para o ajuste inicial do migrante. Mais da metade dos indivíduos solicitou ajuda financeira em sua primeira viagem. Dentre esses, $40,0 \%$ recorreram a parentes, $8,6 \%$ a amigos, $4,1 \%$ a agências de viagens, e o restante está distribuído entre alternativas inexpressivas. Os serviços oferecidos pelas agências de viagens configuram-se mais como arranjos institucionais do que relacionais, mas as informações necessárias para sua utilização estratégica passa certamente pelas conexões sociais. Esses números cumprem, portanto, uma parte do objetivo de evidenciar a presença e o uso das redes sociais na migração de valadarenses aos EUA.

Os mesmos dados, agrupados segundo o período da primeira viagem do migrante, permitem uma visão dinâmica do uso das redes, como mostra a Tabela 6. Evidencia-se a crescente utilização dos recursos financeiros disponibilizados pelas redes sociais. Enquanto que a proporção de migrantes que utilizou somente recursos próprios decai continuamente de $49,2 \%$, no primeiro período, para $42.8 \%$, no período mais recente, o índice que mostra a ajuda oferecida por parentes eleva-se de $36,2 \%$ até $42,8 \%$. É nítida a importância

\begin{tabular}{|c|c|c|}
\hline \multicolumn{3}{|c|}{$\begin{array}{c}\text { TABELA } 7 \\
\text { Fonte de Recursos Financeiros } \\
\text { para o Migrante segundo o sexo na } \\
\text { Primeira Migração Internacional } \\
\text { com Destino aos EUA } \\
\text { Governador Valadares, } 1997\end{array}$} \\
\hline Origem dos & \multicolumn{2}{|c|}{ Sexo } \\
\hline Recursos & Masc. & Fem. \\
\hline Próprios & $47,8 \%$ & $42,3 \%$ \\
\hline Parentes & $37,3 \%$ & $44,6 \%$ \\
\hline Amigos & $9,1 \%$ & $7,7 \%$ \\
\hline Agência viagem & $3,3 \%$ & $4,8 \%$ \\
\hline Outra & $2,5 \%$ & $0,6 \%$ \\
\hline Total $\%$ & 100,0 & 100,0 \\
\hline Total $\left(\mathrm{N}^{2}\right)$ & 276 & 168 \\
\hline \multicolumn{3}{|c|}{$\begin{array}{r}\text { Fonte: Pesquisa amostral } \\
\text { Total de casos: } 456 \\
\text { Casos válidos: } 444\end{array}$} \\
\hline
\end{tabular}

que têm os laços familiares para um indivíduo que deseja levar a termo seu projeto de migrar, mas o efeito principal desse modo de exposição dos dados é o de mostrar, no tempo, o aumento da influência das redes sociais no processo migratório de Governador Valadares.

As pessoas que migram de Governador Valadares para os Estados Unidos, de forma geral, aproveitam bem a assistência financeira disponibilizada pelos laços sociais. No entanto, os homens apresentam uma proporção maior de indivíduos que contam somente com recursos próprios do que as mulheres $(47,8 \%$ e $42,3 \%$, respectivamente), conforme podemos observar na Tabela 7. Supondo que homens e mulheres tivessem condições econômicas semelhantes antes de ingressar no movimento, as mulheres levam vantagem ao migrar, quanto ao uso desse benefício da rede migratória. Além disso, os laços familiares representam um apoio superior às mulheres, que 
conseguiram ajuda financeira através de parentes numa proporção de $44,6 \%$, contra $37,3 \%$ entre os homens.

\section{Conhecidos no destino}

Vimos anteriormente que a maioria dos valadarenses viaja sozinha na primeira experiência migratória (tabela 4). Para que um indivíduo nessa situação tenha melhores condições de se ajustar ao novo ambiente, é muito importante que ele tenha um ponto de apoio confiável no destino. Vejamos, pelos números da Tabela 8, como o migrante valadarense se enquadra nessa questão.

A variável "conhecia no destino" mostra os laços sociais que o potencial migrante possuía antes de ingressar no movimento. Somente $19,8 \%$ relatou não conhecer ninguém nos Estados Unidos em sua primeira viagem, o que destaca a importância de se ter um vínculo pessoal no

\begin{tabular}{|c|c|c|}
\hline \multicolumn{3}{|c|}{$\begin{array}{c}\text { TABELA 8 } \\
\text { Quem o Migrante Conhecia } \\
\text { no Destino } \\
\text { Primeira Migração Internacional } \\
\text { com Destino aos EUA } \\
\text { Governador Valadares, } 1997\end{array}$} \\
\hline $\begin{array}{c}\text { Conhecia } \\
\text { no Destino }\end{array}$ & № & $\%$ \\
\hline Parentes & 254 & 56,1 \\
\hline Amigos & 106 & 23,4 \\
\hline Pessoas da Igreja & 1 & 0,2 \\
\hline Ninguém & 90 & 19,9 \\
\hline Outra & 2 & 0,4 \\
\hline Total & 453 & 100,0 \\
\hline \multicolumn{3}{|c|}{$\begin{array}{l}\text { Fonte: Pesquisa amostral } \\
\text { Total de casos: } 456\end{array}$} \\
\hline
\end{tabular}

\section{TABELA 9}

Quem o Migrante Conhecia no Destino segundo o Período da Primeira Migração Internacional com Destino aos EUA Governador Valadares, 1997

\begin{tabular}{|l|rrr|}
\hline Conhecia no Destino & \multicolumn{3}{|c|}{$\begin{array}{c}\text { Período } \\
87 \text { a } 89\end{array}$} \\
\hline Parentes (\%) & 43 a 86 & 97 \\
\hline Amigos (\%) & 25,8 & 56,8 & 66,4 \\
Ninguém (\%) & 29,5 & 19,7 & 11,2 \\
Outra (\%) & 0,8 & 0,5 & 0,7 \\
\hline Total \% & 100,0 & 100,0 & 100,0 \\
Total (No) & 132 & 183 & 134 \\
\hline
\end{tabular}

Fonte: Pesquisa amostral

Total de casos: 456

Casos válidos: 449

destino. Muitos relataram ter ligações com amigos nos EUA $(23,4 \%)$, mas as conexões familiares predominam $(56,1 \%)$. A Tabela 8 mostra como os laços sociais unem origem e destino do fluxo valadarense, além de evidenciar o parentesco como o principal componente das redes sociais daquela cidade.

Uma vez mais, os dados do survey confirmam a presença das redes migratórias e demonstram de que modo os migrantes se articulam para dela fazerem uso. Para destacar novamente a dinâmica dessas redes, os mesmos dados da Tabela 8 foram redistribuídos, segundo o período da primeira viagem do migrante, na Tabela 9.

Conforme as redes "amadurecem" com o passar do tempo, esperamos que os migrantes relatem um número cada vez maior de laços sociais nos EUA. De acordo com a Tabela 9, o índice de pessoas que declarou não conhecer ninguém no destino cai continuamente. No primeiro período, no qual o movimento ainda não contava com muitos pontos de apoio no destino, $29,5 \%$ das pessoas que decidiram pela migração não conheciam ninguém nos Estados Unidos, antes de viajar pela primeira vez. Já no segundo período, esse número cai para $19,7 \%$, ao mesmo tempo em que se observa a ampliação do movimento na cidade. $\mathrm{O}$ processo migratório vai de tal modo envolvendo a população, até que quase todos tenham pelo menos um conhecido morando nos EUA. No período mais recente, somente $11,2 \%$ do total de migrantes não conhecia ninguém no destino.

As conexões familiares, como tem sido apontado, aparecem novamente como destaque das redes migratórias. A proporção de indivíduos, que possuíam parentes nos EUA antes de embarcar, cresce de $43,9 \%$ no período inicial. para $66,4 \%$ no último período. Os migrantes pioneiros, naturalmente, tinham menos laços familiares no destino. Com o tempo, a experiência migratória é incorporada pela população, até que os migrantes subsequentes tornam-se aptos a utilizar as cada vez mais numerosas conexões de parentes nos Estados Unidos.

Na corrente migratória mexicana, analisada por Massey, os laços de parentesco

\begin{tabular}{|c|c|c|}
\hline \multicolumn{3}{|c|}{$\begin{array}{c}\text { TABELA } 10 \\
\text { Quem o Migrante Conhecia } \\
\text { no Destino segundo o Sexo } \\
\text { Primeira Migração Internaciona } \\
\text { com Destino aos EUA } \\
\text { Governador Valadares, } 1997\end{array}$} \\
\hline \multirow{2}{*}{$\begin{array}{c}\text { Conhecia } \\
\text { no Destino }\end{array}$} & \multicolumn{2}{|c|}{ Sexo } \\
\hline & Masc. & Fem. \\
\hline Parentes (\%) & 50,5 & 65,1 \\
\hline Amigos (\%) & 26,3 & 18,6 \\
\hline Ninguém (\%) & 22,8 & 15,1 \\
\hline Outra (\%) & 0,4 & 1,2 \\
\hline Total $\%$ & 100,0 & 100,0 \\
\hline Total (No) & 281 & 172 \\
\hline \multicolumn{3}{|c|}{$\begin{array}{r}\text { Fonte: Pesquisa amostral } \\
\text { Total de casos: } 456 \\
\text { Casos válidos: } 453\end{array}$} \\
\hline
\end{tabular}


são considerados como uma dos mais importantes bases da organização social da migração, mas somente as ligações familiares masculinas são destacadas, já que esta é uma característica do fluxo México EUA (Massey, 1987). As mulheres brasileiras, neste caso, levam vantagem e utilizam-se mais dos laços familiares que os homens, conforme indicam os dados da Tabela 10.

Conforme podemos observar na Tabela 10 , as mulheres que não conheciam ninguém no destino compõem $15,1 \%$ do total feminino, enquanto que dentre os homens, $22,8 \%$ se identificaram com a mesma situação. As mulheres, portanto, contavam com o apoio de pessoas conhecidas nos EUA, antes mesmo de viajar, numa proporção superior aos homens. Quanto ao tipo de laço existente, os homens se apoiam mais nas relações de amizade do que as mulheres $(26,3 \%$ contra $18,6 \%)$. O grupo feminino, por sua vez, frui dos laços familiares com maior intensidade do que o masculino $(65,1 \%$ contra $50,5 \%)$.

\section{CONCLUSÃO}

Um importante passo no amadurecimento das redes migratórias ocorre quando alguns migrantes começam a se estabelecer nos Estados Unidos. Quando as novidades percorrem a região de origem, mais indivíduos se encorajam e seguem os passos dos pioneiros. A existência de regiões com concentração de parentes, amigos e conhecidos, por sua vez, acelera o desenvolvimento das redes, dando a elas uma forte base nos EUA. No entanto, os pontos de destino encontram-se em diferentes fases quanto à estrutura das redes em cada local. Observamos que a rede social que liga Governador Valadares a Massachusetts é a que melhor disponibiliza seus recursos, e que é essa região nos EUA que mais atrai os migrantes valadarenses.

Quando esses migrantes chegam nos Estados Unidos, obter algum trabalho remunerado passa a ser a preocupação mais imediata. Devido à baixa qualificação de sua mão-de-obra, em termos do país receptor, o migrante brasileiro se insere nos patamares mais baixos do mercado de trabalho norte-americano. Seja no mercado secundário ou no mercado informal, dependendo da perspectiva teórica adotada, o fato é que o migrante valadarense encontra emprego em ocupações de mais baixo status hierárquico, em nichos reservados aos imigrantes. E esses empregos são obtidos através das redes de relações presentes na comunidade migrante. Informações são trocadas, postos de trabalho são vendidos ou sugeridos, e os brasileiros vão chegando e ampliando mais e mais o alcance das redes migratórias.

Como vimos, a migração de valadarenses para os Estados Unidos é fortemente baseada numa organização social que a apóia e sustenta. Massey diz que “(...) a migração internacional é um processo social organizado através de redes forjadas diariamente pelas conexões interpessoais que caracterizam todos os grupos humanos" (Massey, 1987, p. 169). Percebemos a presença dessas conexões cotidianas transformadas no contexto das migrações, e a ampliação do uso das redes com o passar dos anos. As redes migratórias tendem a se tornar auto-suficientes com o tempo devido ao capital social que elas geram aos migrantes em potencial. Contatos pessoais com parentes, amigos e conterrâneos dão aos migrantes acesso a empregos, hospedagem e assistência financeira nos Estados Unidos.

* Wilson Fusco é Pesquisador do NEPO (Núcleo de Estudos de População)-UNICAMP e doutorando em Demografia no IFCH-UNICAMP.

\section{NOTAS}

1. Este artigo tem por base a dissertação de mestrado intitulada "Redes Sociais nas Migraçōes Internacionais: o caso de Governador Valadares", defendida em dezembro de 2000 no Programa de Mestrado em Sociologia do IFCH-UNICAMP.

2. Os dados utilizados neste trabalho resultam de uma pesquisa de campo por amostragem aleatória realizada em Governador Valadares/ MG, em julho/agosto de 1997. O trabalho de campo aconteceu em duas etapas: a primeira, na qual foram visitados 2566 domicílios, com o objetivo de localizarmos aquelas residências em que pelo menos um morador tivesse experiência migratória internacional; a segunda etapa consistiu na aplicaçăo dos questionários em 467 domicílios, os quais foram encontrados na primeira etapa.

3. Este é um depoimento da própria autora, em seu livro Brasileiros Longe de Casa.

\section{REFERÊNCIAS BIBLIOGRÁFICAS}

ASSIS, G. O.
(1995) Estar aqui, estar lá...uma cartografia da vida em dois lugares. Dissertação (Mestrado em Antropologia) - Programa de Pós-Graduação em Antropologia Social, UFSC.

ASSIS, G. O.

(1999) "Estar aqui..., estar lá... uma cartografia da emigração valadarense para os EUA". In: REIS, R.; SALES, T. (orgs.). Cenas do Brasil migrante. São Paulo. Editora Boitempo.

BICALHO, J. V.

(1989) Yes, eu sou brazuca. Governador Valadares, Ibituruna.

FUSCO, W.

(2000) Redes Sociais na Migração Internacional: o caso de Governador Valadares. Dissertação (Mestrado em Sociologia) - Programa de Pós-Graduação em Sociologia, IFCH-UNICAMP.

MARTES, A. C. B.

(1998) Imigrantes brasileiros em Massachusetts. Tese (Doutorado) - USP.

MARTES, A. C. B.

(1999) "Os imigrantes brasileiros e as igrejas em Massachusetts". In: REIS, R.; SALES, T. (orgs.). Cenas do Brasil migrante. Sāo Paulo, Editora Boitempo.

MASSEY, D. S. et al.

(1987) Return to aztlan. Los Angeles, University of California Press.

RIBEIRO, G. L.

(1999) "O que faz o Brasil, Brazil: jogos identitários em São Francisco". In: REIS, R.; SALES, T. (org.). Cenas do Brasil migrante. São Paulo, Editora Boitempo.

SALES, T.

(1995) "O trabalhador brasileiro no contexto das novas migraçōes internacionais". In: VV.AA. O trabalho no Brasil no limiar do século XXI. São Paulo, Editora LTr.

SALES, T.

(1999) Brasileiros longe de casa. São Paulo, Editora Cortez.

SCUDELER, V.

(1999) "Imigrantes valadarenses no mercado de trabalho dos EUA". In: REIS, R.; SALES, T. (orgs.). Cenas do Brasil migrante. São Paulo, Editora Boitempo.

SCUDELER, V.

(1999) $A$ inserção de imigrantes brasileiros no mercado de trabalho dos EUA. Dissertaçāo (Mestrado) - Instituto de Economia/UNICAMP.

SOARES, W.

(1995) Emigrantes e investidores: redefinindo a dinâmica imobiliária na economia valadarense. Dissertação (Mestrado) - Programa de Pós-Graduação do IPPUR/UFRJ.

TILLY, C.

(1990) "Transplanted networks". In: YANS, M. V. Immigration reconsidered: history, sociology, and politics. Nova York, Oxford University Press. 